\title{
ACCELERATING EFFECTS ON GELLING OF SBR-LATICES
}

E. Tanaka, E. Shiratsuchi, T. Kotani, I. Toshimizu (Japan Synthetic Rubber Co., Ltd.)

In studies on manufacturing of foam rubbers, it was found that gelling of SBR-latices is accelerated by adding water-soluble salts of amino acid such as gelatine, glue and sodium glutaminate to latices.

It was considered that gelling of SBR-latices is accelerated due to the creaming action to latex in the case of gelatine and glue, and due to zinc ions that is induced by the reaction with zinc oxide in the case of sodium glutaminate.

In this case, the quantity of induced zinc ions differs by $\mathrm{pH}$ and temperature of compounded latices, and also by the chemicals added.

\section{各種純ゴムの高周波振動特性}

（昭和37年7月17日 受理）

\section{松下 秀夫* 橋田 泰三* \\ 藤島 弘康*}

要 㕂 加硫ゴムの比較的低周波領域における動特性は今までにかなり詳しく研品されているが，100 cps 以上の高周波領域に抢りる挙動についてはあまり明加されていない。ここでは縱波共振法利用して各種 純ゴムの $100 \mathrm{cps} \sim 2,000 \mathrm{cps}$ の領域における緥波の伝播速度，吸收係数や動的ヤング率，損失係数を求めた， その結果はつぎのようにまとめること加出来る。(1)伝播速度や勳的ヤング率で大きい周波数依存性を示すグ ループ (IIR, NBR: Hypalon) 上俵存性の少いグループ (NR, SBR, BR, Silicone) と更に活グループの中 間的なグループ (CR, EPR, Urethane) との3つに大别出来る。(2)吸収係数や損失係数についても上の周波 数依存性の大さい6のが一般に大きい值を示す。

\section{1. 緒 論}

加硫ゴムの比較的低周波領域における動特性は今まで に加なり詳しく研究されており，実用上も防振ゴムその 他の設計・解析等に非常に役立っている. しかし $100 \mathrm{cps}$ 以上の周波数（とれは機械的周波というよりむしろ音波 や超音波の領域になる）に方ける加硫ゴムの挙動は今迄 多少の文献 ${ }^{103}$ はあるけれよ゙あ，未だ允分実用上役立つ ような形になっていない，たとえば理諭的には粘弾性体 に振動ヒズミを与える場合，一般化された Maxwell Model を使用して動的弹性率 $G^{\prime}$ や動的損失 $G^{\prime \prime}$ の周 波数傸存性加下記の如く示されている。（図 1 参炤）

$$
G^{\prime}(\omega)=\sum_{i=1}^{n} G_{i} \frac{(\omega \tau \mathrm{i})^{2}}{1+(\omega \tau \mathrm{i})^{2}}
$$

†本報を〔ゴムの高周波振動特性に関する研究（第 1 報)】とする。

*東洋ゴム工業株式会社中央研究所

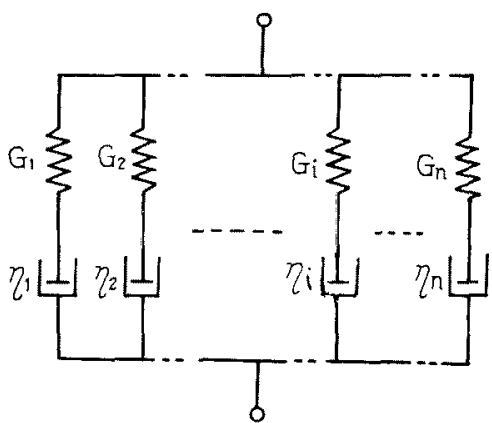

四1(a)一般化された Maxwell Model

$G^{\prime \prime}(\omega)=\sum_{i=1}^{n} G_{i} \frac{\omega \tau i}{1+(\omega \tau i)^{2}}$

但し $\tau \mathrm{i}=\eta_{i} / G_{i}$

又 Ferry の温度〜時閭換算法則要周波数低存性考无 


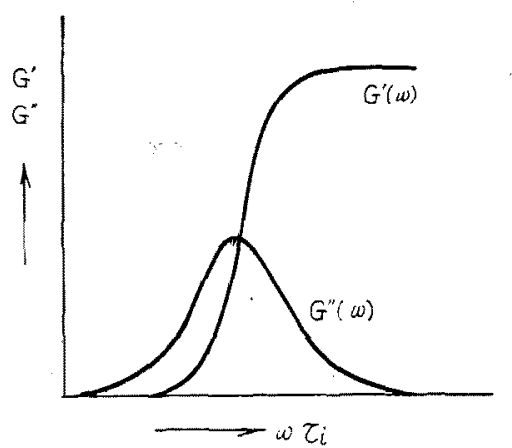

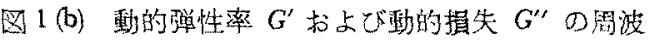
数依存性

る場合には極めて有力である。

$$
\begin{aligned}
& G^{\prime}(\omega, T)=\frac{\rho T}{\rho_{S} T_{S}} G^{\prime}\left(\omega a_{T}, T_{S}\right) \\
& \varepsilon(\omega, T)=\frac{G^{\prime \prime}(\omega, T)}{G^{\prime}(\omega, T)}=\varepsilon\left(\omega a_{T}, T_{S}\right) \\
& \text { 但 }\left\{T, T_{S}\right. \text { : 試験温度と基準温度 }
\end{aligned}
$$

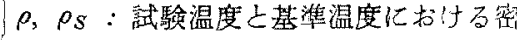

$$
\begin{aligned}
& \text { 度 } \\
& a_{T} \quad \text { : 周波数温度换算係数 }
\end{aligned}
$$

こ机らは現象を一般的に広く説明するのには適当です

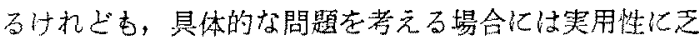
しいものよいえる。

ここで我々が対象ししているのは $100 \mathrm{cps} \sim 2,000 \mathrm{cps}$

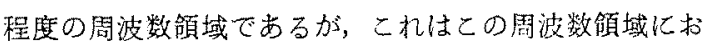
いて鉄道車輛や自毁車等使用されているゴム製品が所 定の防振効果の期待できない場合がしばしば経験されて いるためである。これはゴム自身の固有振動数がその頒 域にあるためで，金属バネで良く知られているサーシン グと同じ現象之考えられる。我々は加硫ゴムのサージン グをよく理解するためにその材筫や形状等の影翌を謂へ るとと定目的としてこの奏験を始めた，ここては先つる の㫷本亡なる各種ゴム加硫物の音波の伝播速度や吸收係 数 (acoustic attenuation) および機械的䌽数に换算した 趿的ヤング率や損失係数の $100 \mathrm{cps} \sim 2,000 \mathrm{cps}$ の頜域に

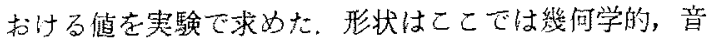
饗学的に無視できる条件をえらんだ。

\section{2. 実験方法およじ理論}

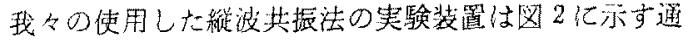
りで古る。先つ CR 発振器に䧓波数既知の正弦波交流 電压発生させ，乙れ在出力增幅器で数百Vに增幅して
チタン酸バリウムの振勘台を加振する．この振動台上に ゴム試料は接着されていて振動台に発生した音波は詿料

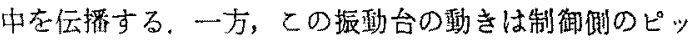
ク・アップによって険出し，定猳幅装置にフイード・バ ックして䌾波数が变化しても振動台の掁幅は一定に保た れる。践料の下端加ら加えられた縱波は試料中を伝播し てその自由端で反射されるが，試料長lとこの維波の汥 嘸 $\lambda$ しが $l \cong n \lambda / 4(n=1,3,5, \cdots \cdots)$ の関係にある場合 に共振が生じる。(この関係は瘚密には成立しない，補 正した関係式については後出の式を参照すること・）自 由端の变位は検出側のピック・アップによって検出し， 真空管電死計で読み上る。これらのピック・アップは平 行板コンデンサーと同様の原理で雨極間の変位を容量变 化で検出するものである，更にブラウン管オッシロスコ ーブで其振の礁認を行っている.

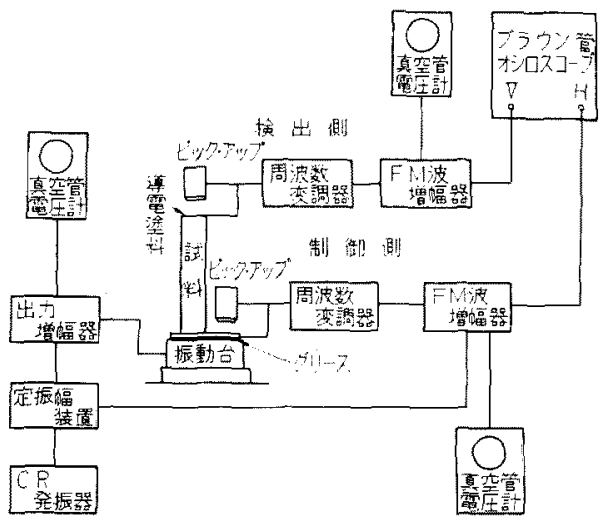

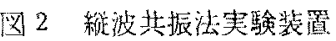

試料は細長い川柱形で音響学的な条件加ら $l l d>4$, $\lambda / d>6(l:$ 試料長, $d:$ 試料直径, $\lambda:$ 积放の波長) を渾足するものとした，てのようにして求めた共振曲線 の一例を因 3 亿示守。ささてとの場合の運動方程式は次式 で示される。

$$
\rho \frac{\partial^{2} \xi}{\partial t^{2}}-E^{\prime}-\frac{\partial^{2} \xi}{\partial x^{2}}-\eta \frac{\partial^{3} \xi}{\partial x^{2} \partial t}=f
$$

但し $\rho:$ 試料の密度

$E^{\prime}, \eta:$ 試料の動的ヤング率㚭よび粘性䋆数

$\xi$ : 平衝位置加らの変位

$f:$ 外 力

これから若干の仮定を入れて解くと音波の伝播速度 $C$ 上吸収係数 $\alpha$ について次式加得られる。

$$
\left\{\begin{array}{l}
C \cong \frac{2 l}{n \pi} \omega_{0}\left(1+\frac{1}{8} \cdot \frac{1}{Q^{2}}\right) \\
\alpha \cong \omega_{0} / 2 Q C_{n}
\end{array}\right.
$$


表1 配合および加硫条件

\begin{tabular}{|c|c|c|}
\hline 号 & 合一重 量 比 & 加硫条件 \\
\hline NR & RMA开4-100，亜鉊華-5，硫黄-2.5，ステアリン酸-1，促 DM-1，老 D-1 & $141^{\circ} \mathrm{C} \times 45^{\prime}$ \\
\hline SBR & SBR\#1500-100，亜鉊苇-5，硫黄-2，促 DM-1 & $141^{\circ} \mathrm{C} \times 60^{\prime}$ \\
\hline NBR & Hycar\#1041-100, 刺鉛萧-5, 硫黄-1.5, 促 DM-1 & $141^{\circ} \mathrm{C} \times 60^{\prime}$ \\
\hline IIR & Polysar Butyl井400-100，西鉛華-5，硫黄-2，ステアリン酸-3，促 TT-1 & $141^{\circ} \mathrm{C} \times 60^{\prime}$ \\
\hline GR & Neoprene W-100, 亜鉛蕉-5, 酸化マグネシウム-4, NA-22-0.3, 花 A-1 & $141^{\circ} \mathrm{C} \times 45^{\prime}$ \\
\hline Cis 4 & Cis 4-100，两鉊華-5，硫黄-2，ステアリン酸-1，促 CZ-1，老 D-1 & $147^{\circ} \mathrm{C} \times 60^{\prime}$ \\
\hline Diene & Diene-100, 亚鉛華-5，ステアリン酸-1，硫黄-2，促 CZ-1，老 D-1 & $147^{\circ} \mathrm{C} \times 60^{\prime}$ \\
\hline EPR & $\begin{array}{l}\text { Enjay EPR MD-460-100, 雨鉛華-5, ステアリン酸カルシウム }-2 \text {, 硫㣴-0.32, } \\
\text { Di-Cup 40C-6.75 }\end{array}$ & $153^{\circ} \mathrm{C} \times 60^{\prime}$ \\
\hline Hypalon & Hypalon\#20-100，ステアリン酸-2.5，リサージ-40，促 M-3 & $153^{\circ} \mathrm{C} \times 45^{\prime}$ \\
\hline Urethane & Adiprene L-100, MOCA-11.7 & $100^{\circ} \mathrm{C} \times 180^{\prime}$ \\
\hline Silicone & KE-660 (信越化学) -100 & $\begin{array}{l}1 \text { 次 } 120^{\circ} \mathrm{C} \times 30^{\prime} \\
2 \text { 次 } 200^{\circ} \mathrm{C} \times 20 \mathrm{hrs}\end{array}$ \\
\hline
\end{tabular}

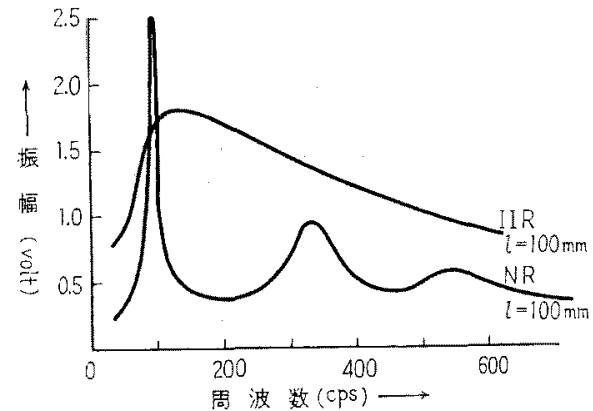

国 3 共振曲線の一例

但し $\omega_{0}$ : 共振角周波数

$f_{0}$ : 其振周波数 $\left(=\omega_{0} / 2 \pi\right)$

$C_{0}=\frac{4 l}{n} \cdot f_{\mathrm{g}}$

$1 / Q=\left(\omega^{\prime \prime}-\omega^{\prime}\right) / \omega_{0}\left(\omega^{\prime}, \omega^{\prime \prime}\right.$ は共振曲線において 共振振幅の $1 / \sqrt{2}$ の掁幅を示す解周波数， $\left.\omega^{\prime \prime}>\omega^{\prime}\right)$

更に機械的係数に換算すると軘的ヤング率 $E^{\prime}$ ，むよ

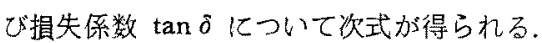

$$
\left\{\begin{array}{l}
E^{\prime} \cong \rho C_{v}^{2}\left(1-\frac{1}{2} \cdot \frac{1}{Q^{2}}\right) \\
\tan \delta \cong 1 / Q
\end{array}\right.
$$

実験で求められる值は共振居周波数 $\omega_{3}$ と共振曲線加 ら求められるQの2つである．実験に使用したゴム配 合および加硫条件は表 1 の通りである.なお振勒台の变

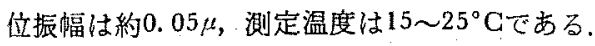

\section{3. 実験結果および考察}

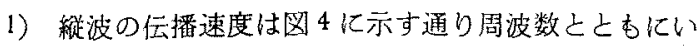

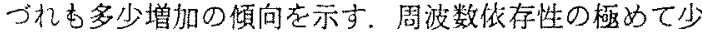
ないグループとしては NR, SBR, BR (Cis 4 およじ Diene) があり，加なりきい周波数依存些走すグル 一プとしてはIIR, NBR, Hypalon がある. CR, EPR (ethylene-propylene copolymer), Silicone, Urethane どは両グループの中間的存在といえる。周波数依存性の 大きいものは一次結合（架橋）の此較的不完全なポリマ 一や凝集エネルギーの大きいポリマーとして一応理解て きる。(しかしと机らのポリマーについては本実験の縰
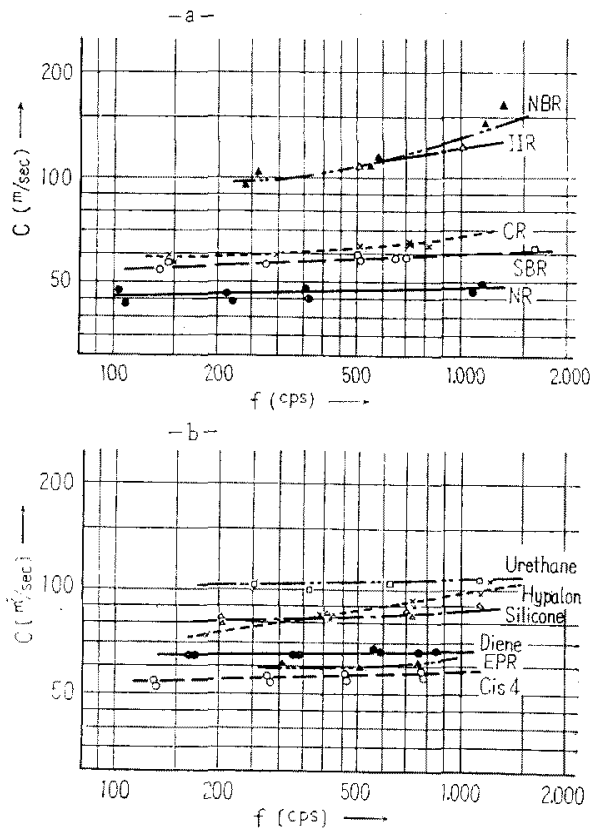

図 4 伝播速度 $(C)$ 已䦌波数 $(f)$ の関係 

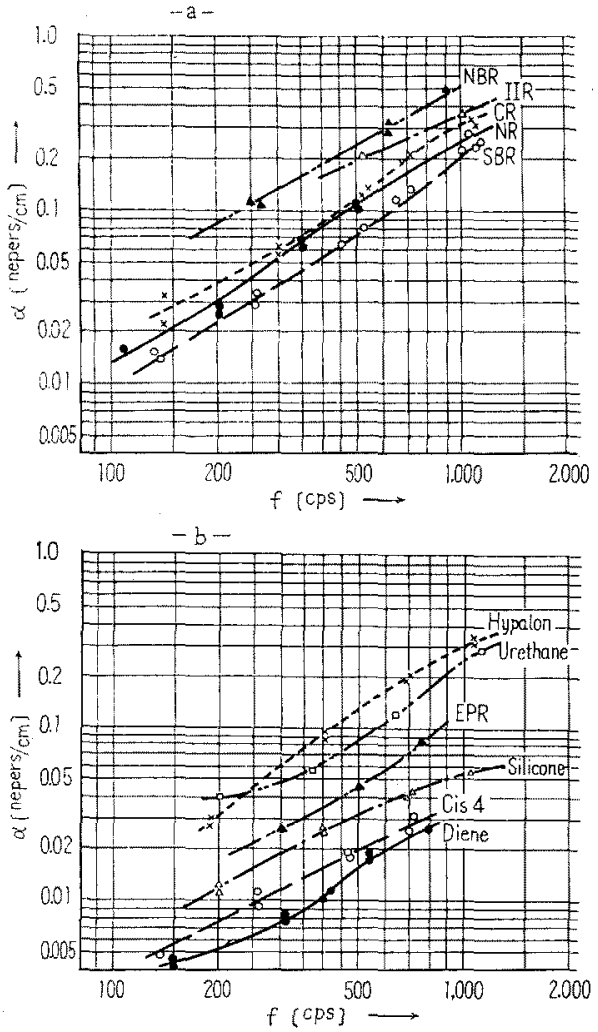

図 5 吸取係数 $(\alpha)$ 之周波数 $(f)$ の関係

波共振法はあまり適した試驗方法上はいえない，共振曲 楾はかなり㕕湢のものとなり，加つ近似計算委精度が瑟 くなるためである・）

2) 吸收係数は図 5 に示す通り伝播速度の場合亡異って 周没数の增加と之もにかな上䒜する。これはホりマー 中の粘性機構が主要因子になるので，その変形速度即占 周波数に大きく佊存する6のとして理解できる。小縰 波の伝播速度で入きい周波数依存性を示すグループ (IIR NBR, Hypalon) は吸収倸数も一般に大きい値在

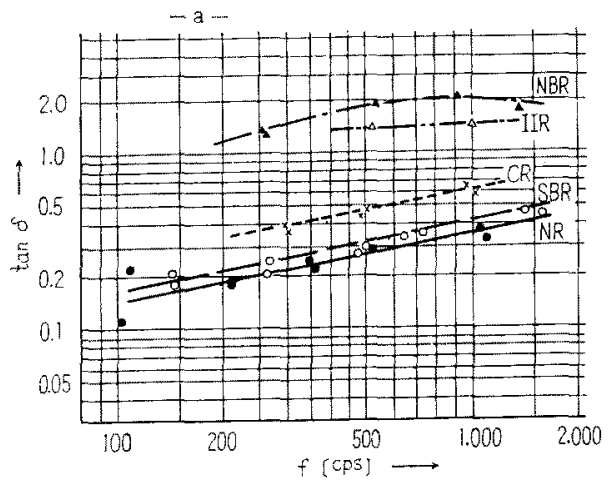

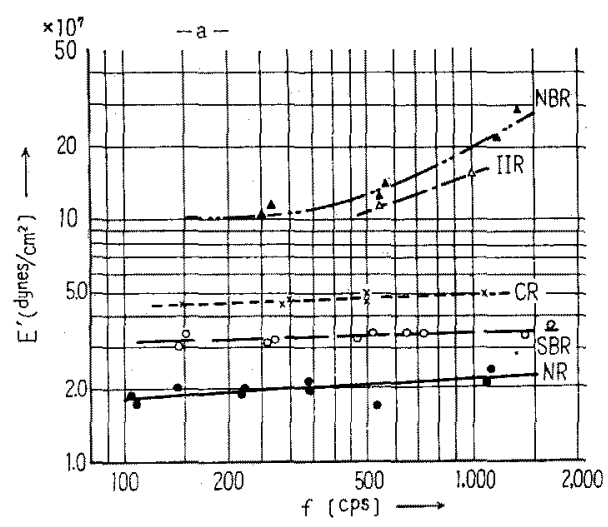

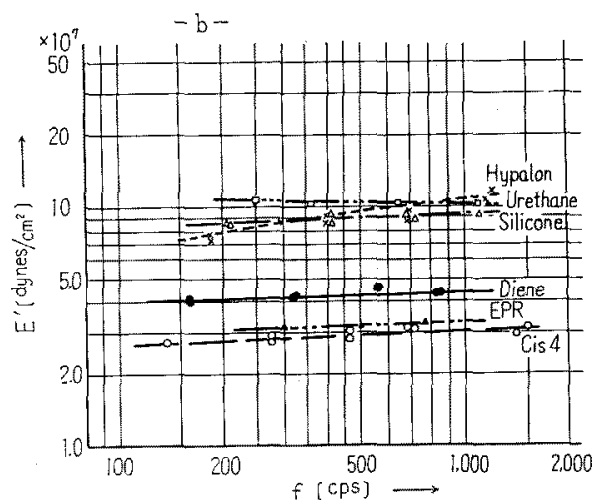

図 6 勤的ヤング率 $\left(E^{\prime}\right)$ 之周波数 $(f)$ の関係 香す。

3）動的ヤング率は図 6 に示す通り伝播速度の場合とよ く似大傾向を示す，IIR，NBR. Hypalon は周波数俵存 性の大きいグループとして上と同様に分類できるが，そ の他のポリマーの依存性は極く僅かである。

4) 損失係数は図 7 亿示す通り吸收係数の場合之よく似 た傾向を示す，伝播速度や動的ヤング率の閣波数依存性 の大きいグループは一般に大きい損失係数を示し， Urethane, EPR，CR がこれにつづいて大き，NR，

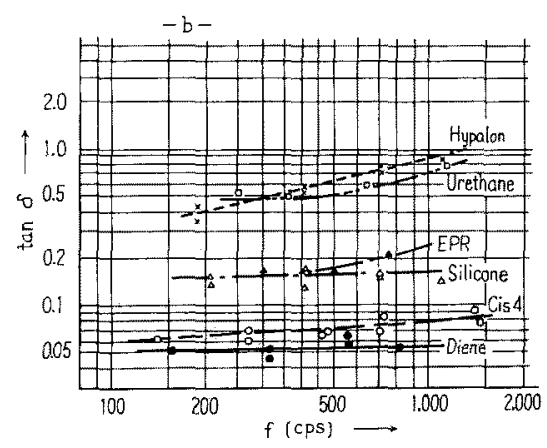

图 7 損失係数 $(\tan \delta)$ 上䦌波数 $(f)$ の閣係 
SBR, Silicone, BR が比較的低い損失係数索示すが特に BR はもっとも低く今後タイヤや防振ゴム等の動的に莉 酷な条件で使用される用途に適しているととを示してい る.

\section{4. 結 論}

緃波共振法によって数種類の純ゴム加硫物の音響およ び機械特性を $100 \mathrm{cps} \sim 2,000 \mathrm{cps}$ の周波数領域で测定し たその結果を次のようにまとめることが出来る。

1) 伝播速度や動的ヤング率で大きい周波数依存性を示 すのは IIR, NBR, Hypalon のグループで NR, SBR, BR, Silicone のグループは比較的周波数依存性が少い. CR, EPR, Urethane は両グループの中間的存在であ Z.
2) 吸収係数や唄失係数についても上の周波数依存性の 大きいものが一般に大きい.

3)乙れらの特性はいずれる周波数の增加上ともにいる れも多少增加する傾向を示す。

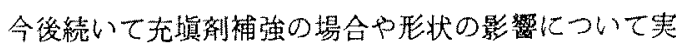
験を進める予定である。悠りにこの実験に対して種々御

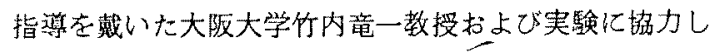
てもらった当社賀美敏行君江梁く感謝する。

\section{文献}

1) D.G. Ivey et al : J. Appl. Phys., 20, 486 (1949)

2) R.S. Witte et al: J. Appl. Phys., 20, 481 (1949)

3) A.W. Nolle: J. Polymer Sci., 5, I (1950)

日本ゴム協会第29回通常総会．研究発表科演会（昭和 37年5月9日）にて発表.

\section{MEGHANICAL AND ACOUSTIC PPOPERTIES OF RUBBER VULCANIZATES AT AUDIOFREQUENCIES (PART I)}

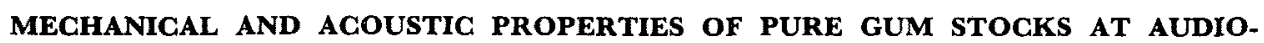 FREQUENCIES}

H. Matsushita, T. Hashida, H. Fujishima (The Toyo Rubber Ind. Co., Ltd.)

Now available are few data of rubber vulcanizates for mechanical and acoustic uses at audiofrequencies. In this paper mechanical and acoustic properties of various pure gum stocks are measured at frequency range from $100 \mathrm{cps}$ to $2,000 \mathrm{cps}$ by means of longitudinal wave resonance method.

Dynamic moduli and propagation velocities in elastomers increase slightly with increasing frequencies, and mechanical loss factors and acoustic attenuations increase more rapidly. Elastomers, here tested, are classified in three groups as follows:

(Group 1); IIR, NBR and Hypalon whose properties show considerable dependency on frequencies.

(Group 2); NR, SBR, BR and Silicone are less dependent on frequencies.

(Group 3); CR, EPR and polyurethane are between (Group 1) and (Group 2). 